\title{
SOME OBSERVATIONS ON THE FINE STRUCTURE OF ARMADILLO SPERMATOZOA
}

\author{
F. NAGY AND R. H. EDMONDS \\ Department of Anatomy, The Albany Medical College of Union University, \\ Albany, New York, U.S.A.
}

(Received 10th April 1973)

In the present report, we present certain facets of the fine structure of the epididymal spermatozoa of an edentate, the nine-banded armadillo, Dasypus novemcinctus mexicanus. Although numerous investigators have devoted considerable attention to the morphology of spermatozoa using both transmission (Cleland \& Rothschild, 1959; Bedford, 1965; Blom \& Birch-Andersen, 1965; Nicander \& Bane, 1966; Fawcett \& Ito, 1965; Phillips, 1970; Pedersen, 1970; Phillips, 1972) and scanning (Koehler, 1970) electron microscopes, the armadillo represents a mammalian species in which the fine structure of the spermatozoa has not been investigated. While numerous features common to most mammalian spermatozoa have been observed in the armadillo, we report here some of the more distinctive features.

Sexually mature, male, nine-banded armadillos were examined during April and May. The animals were maintained for brief periods in the laboratory before they were killed with an overdose of Nembutal. Under light Nembutalinduced anaesthesia, the epididymides were removed and immediately immersed in a phosphate-buffered paraformaldehyde-glutaraldehyde solution (Karnovsky, 1965). The epididymides were divided into initial, middle and terminal segments and minced tissue was then placed in fresh fixative for $2 \mathrm{hr}$. Tissues were post-fixed in $1 \%$ phosphate-buffered osmium tetroxide for an additional $2 \mathrm{hr}$, dehydrated in a graded series of ethanols, infiltrated and embedded in Epon 812 (Finck, 1960). Thin sections for electron microscopy were cut using glass knives and were stained with uranyl acetate and lead citrate to enhance contrast. Sections were examined in an RCA-EMU-3E electron microscope with a modified condenser at accelerating voltages of 50 and $100 \mathrm{kV}$.

The frontal plane of the sperm head is paddle-shaped, whereas the sagittal profile is ensiform and exhibits an acrosome with three distinct regions: an apical portion, a thick main segment and a thin equatorial segment. The main portion of the acrosome is characterized by a marginal thickening which extends to the junction of the main portion and the equatorial segment. The contents of the three acrosomal segments appear to be uniformly electron-dense (Pl. 1, Fig. 1).

In keeping with the general morphology of mammalian spermatozoa, the paddle-shaped armadillo sperm head resembles that of several species including bulls, rams, boars, guinea-pigs (Nicander \& Bane, 1966), chinchillas (Fawcett $\&$ Phillips, 1969) and rabbits (Calvin \& Bedford, 1971). The ensiform sagittal 
profile is not unlike that seen in the macaque (Fawcett, 1970) and boar (Jones, 1971).

Posterior to the equatorial segment of the acrosome, the plasma membrane closely parallels the contour of the nucleus. Here, the inner aspect of the plasma membrane is modified to form the postacrosomal dense lamina (postnuclear cap) which exhibits a periodic substructure when examined at low magnifications (Pl. 1, Fig. 2). In favourable sections examined at higher magnifications, the dense lamina is seen to consist of a regular pattern of delicate tubules (Pl. 1, Fig. 3) arranged at an angle oblique to the antero-posterior axis of the sperm head. It is not yet clear whether these tubules are purely structural or whether they subserve a more complex function such as transport.

A structure found in armadillo spermatozoa which we have not seen described in other species is a short 'bilaminar plate' (PI. 1, Fig. 4). This structure consists of two dense sheets separated by a narrow region of low electron density and seems to bridge the gap between the posterior part of the equatorial segment and the anterior end of the well-defined postacrosomal dense lamina. For a short distance posterior to the equatorial segment, there is no dense lamina on the inner aspect of the plasma membrane. Rather, an amorphous dense material occupies this region and serves to join the plasma membrane with the bilaminar plate. The plate seems to be the attachment site for the plasma membrane in the most anterior part of the postacrosomal region. It is at this point that the plasma membrane becomes closely applied to the sperm nucleus. The bilaminar plate was not observed to be contiguous with either the equatorial segment or the nuclear envelope.

The middle piece of the armadillo spermatozoon is generally typical of other mammalian species. A thick, helical mitochondrial sheath surrounds the contractile elements of the sperm tail. The mitochondria (Pl. 1, Fig. 5) are somewhat unusual in that they possess concentrically arranged, longitudinally disposed cristae. The spiral mitochondrial sheath is arranged at an angle of about 15 to $20^{\circ}$ with respect to the long axis of the spermatozoon. Usually, three mitochondria are seen in a transverse section of the middle piece.

As in other mammalian spermatozoa, the armadillo presents an array of nine outer or coarse fibres associated with the axial filament complex (Pl. 1, Fig. 6).

\section{EXPLANATION OF PLATE 1}

Fig. 1. Sagittal section of an armadillo sperm head from the middle segment of the epididymis illustrating apical, main and equatorial segments of the acrosome. A substantial subacrosomal space is present. $\times 31,500$.

Fig. 2. Transverse section of a sperm head illustrating the periodicity associated with the postacrosomal dense lamina. $\times 66,000$.

FIG. 3. Sagittal section of a sperm head showing some of the tubular elements (arrows) of the postacrosomal dense lamina. $\times 318,000$.

FIG. 4. Sagittal section of a sperm head illustrating the junction of the equatorial segment with the postacrosomal region. A bilaminar plate (arrow) can be seen just caudal to the termination of the equatorial segment. $\times 74,500$.

Fig. 5. Transverse section through mitochondria of the mid-piece sheath illustrating concentric cristae with a large, dense central core. $\times 55,000$.

Fig. 6. Transverse section through sperm mid-piece illustrating contractile elements surrounded by a thick mitochondrial sheath. Note that coarse fibres ' 1 ', ' 5 ', ' 6 ' and ' 9 ' are larger than the remainder. $\times 59,500$ 
PI.AT: 1

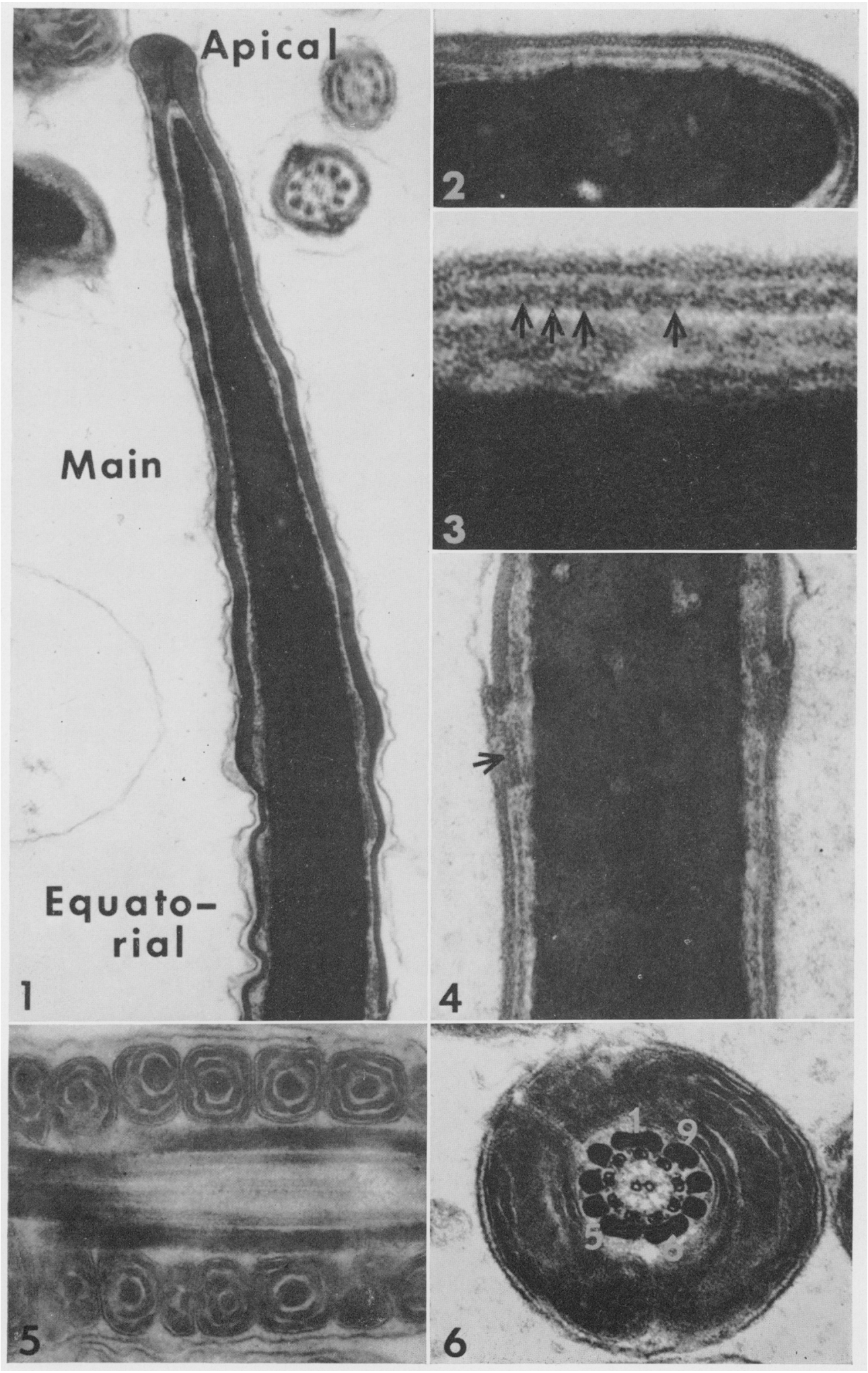


In the central region of the middle piece, coarse Fibres '2', ' 3 ', ' 4 ', ' 7 ' and ' 8 ' are of similar size and round in cross-section, whereas Fibres ' 1 ', ' 5 ' and ' 6 ' are larger and biconcave. Fibre ' 9 ' is ovoid and consistently intermediate in size between Fibres ' 1 ', ' 5 ' and ' 6 ' and Fibres '2', ' 3 ', ' 4 ', ' 7 ' and ' 8 '. This difference is observed consistently and is believed to be real. The intermediate size of Fibre ' 9 ' would seem to mitigate against an even concentration of power on two sides of the spermatozoon. It would be of interest to know how the different dimensions of the coarse fibres affect sperm movements.

This investigation was supported by PHS Grant GRS-FR5394 and the Albany Medical College.

\section{REFERENCES}

BEDFORD, J. M. (1965) Changes in fine structure of the rabbit sperm head during passage through the epididymis. F. Anat. 99, 891.

Blom, E. \& Birch-ANDERSEN, A. (1965) The ultrastructure of the bull sperm. Nord. VetMed. 17, 193.

Galvin, H. I. \& Bedford, J. M. (1971) Formation of disulphide bonds in the nucleus and accessory structures of mammalian spermatozoa during maturation in the epididymis. F. Reprod. Fert. Suppl. 13, 65.

Gleland, K. W. \& Rothschild, LoRd (1959) The bandicoot spermatozoon: an electron microscope study of the tail. Proc. $R$. Soc. B, 150, 24.

Fawcett, D. W. (1970) A comparative view of sperm ultrastructure. Biol. Reprod. Suppl. 2, 90.

FAwCETt, D. W. \& Ito, S. (1965) The fine structure of bat spermatozoa. Am. F. Anat. 116, 567.

FAwCETr, D. W. \& Phillips, D. M. (1969) Observations on the release of spermatozoa and on changes in the head during passage through the epididymis. 7. Reprod. Fert. Suppl. 6, 405.

FINCK, H. (1960) Epoxy resins in electron microscopy. 7. biophys. biochem. Cytol. 7, 27.

JoNEs, R. G. (1971) Studies on the structure of the head of boar spermatozoa from the epididymis. 7. Reprod. Fert. Suppl. 13, 51.

KARNOvSKy, M. J. (1965) A formaldehyde-glutaraldehyde fixative of high osmolality for use in electron microscopy. 7. Cell Biol. 27, 137A.

KozHLER, J. K. (1970) A freeze-etching study of rabbit spermatozoa with particular reference to head structures. F. Ultrastruct. Res. 33, 598.

NiCANDER, L. \& BANE, A. (1966) Fine structure of the sperm head in some mammals, with particular reference to the acrosome and the subacrosomal substance. $Z$. Zellforsch. mikrosk. Anat. 72, 496.

Pedersen, H. (1970) Observations on the axial filament complex of the human spermatozoon. $\mathcal{F}$. Ulirastruct. Res. 33, 451.

Phillips, D. M. (1970) Development of spermatozoa in the woolly opossum with special reference to the shaping of the sperm head. 7. Ultrastruct. Res. 33, 369.

Phillips, D. M. (1972) Substructure of the mammalian acrosome. f. Ultrastruct. Res. 38, 591. 